\title{
Internodal Analysis of Avicennia marina in the Western Arabian Gulf
}

\author{
Hanan Almahasheer* \\ Department of Biology, College of Science, Imam Abdulrahman Bin Faisal University (IAU), Dammam, Saudi Arabia
}

The growth of Avicennia marina (A. marina) was not previously assessed using internodal analysis in the Western Arabian Gulf. The node production in 40 branches/axillary shoot in Syhat city, Saudi Arabia, ranged from 6 to 9 nodes $y^{-1}$. Moreover, the annual cycles of the internodal length represent the branch growth rate in centimeters per year (ranged from 12 to $43 \mathrm{~cm}$; median of $19 \mathrm{~cm}$ ) for minima to minima point and (from 15 to $46.5 \mathrm{~cm}$; median of $25.5 \mathrm{~cm}$ ) for maxima to maxima point. The results obtained in this study are fundamental for various applications, ranging from the planning of restoration and monitoring activities to reproduction estimates and establishing a useful baseline to assess responses to climate change via simple measurements. In particular, mangrove species are important as nurseries for many species for food and shelter, carbon sinks,

\section{OPEN ACCESS}

Edited by:

Iñigo Muxika,

Technological Center Expert in Marine and Food Innovation (AZTI), Spain

Reviewed by:

Thadickal V. Joydas, King Fahd University of Petroleum and Minerals, Saudi Arabia

Emily Dangremond,

Roosevelt University, United States

*Correspondence:

Hanan Almahasheer halmahasheer@iau.edu.sa

Specialty section: This article was submitted to Marine Ecosystem Ecology, a section of the journal Frontiers in Marine Science

Received: 21 April 2021 Accepted: 30 June 2021 Published: 29 July 2021

Citation: Almahasheer H (2021) Internodal Analysis of Avicennia marina in the Western Arabian Gulf.

Front. Mar. Sci. 8:698596. doi: 10.3389/fmars.2021.698596 and coastal protection.

Keywords: phenology, analysis, age, plant, growth

\section{INTRODUCTION}

Mangroves inhabit intertidal zones of tropics and subtropics (Tomlinson, 1986) and provide many ecosystem services (Barbier et al., 2011). Avicennia marina (A. marina) is the most diverse mangrove species worldwide (Tomlinson, 1986). Two species of mangrove, such as A. marina from Avicenniaceae and Rhizophora mucronata from Rhizophoraceae, are found in the Arabian Gulf (Zahed et al., 2010); however, A. marina is the dominant mangrove species in the Arabian Gulf (Price et al., 1993; Almahasheer et al., 2018). While phenological studies of A. marina on some parts of the Arabian Gulf exist, e.g., Hegazy (1998) and Yasseen and Abu-Al-Basal (2008), estimation of their node production per branch per year and their annual growth in centimeter and plastochron index has not been reported in the Western Arabian Gulf. The importance of estimating internodal production and growth of mangroves in the Arabian Gulf can help future studies in this area to better understand their status and the contribution of A. marina to the adjacent ecosystems. These data also help balance global reports with information about an area that was overlooked.

\section{MATERIALS AND METHODS}

\section{Sampling}

Avicennia marina internodal measurements were conducted in July 2019 at Syhat city $\left(26^{\circ} 30^{\prime} 28^{\prime \prime} \mathrm{N}\right.$ $50^{\circ} 02^{\prime} 30^{\prime \prime} \mathrm{E}$ ), Eastern Province, Kingdom of Saudi Arabia, which is situated on the coast of the Western Arabian Gulf (Figure 1). The number of samples selected for the internodal analysis in this study was 40 trees. This number of samples has been validated before, e.g., Duarte et al. (1999) selected eight Avicennia alba, 26 Sonneratia caseolaris, and 12 Rhizophora apiculata trees in 


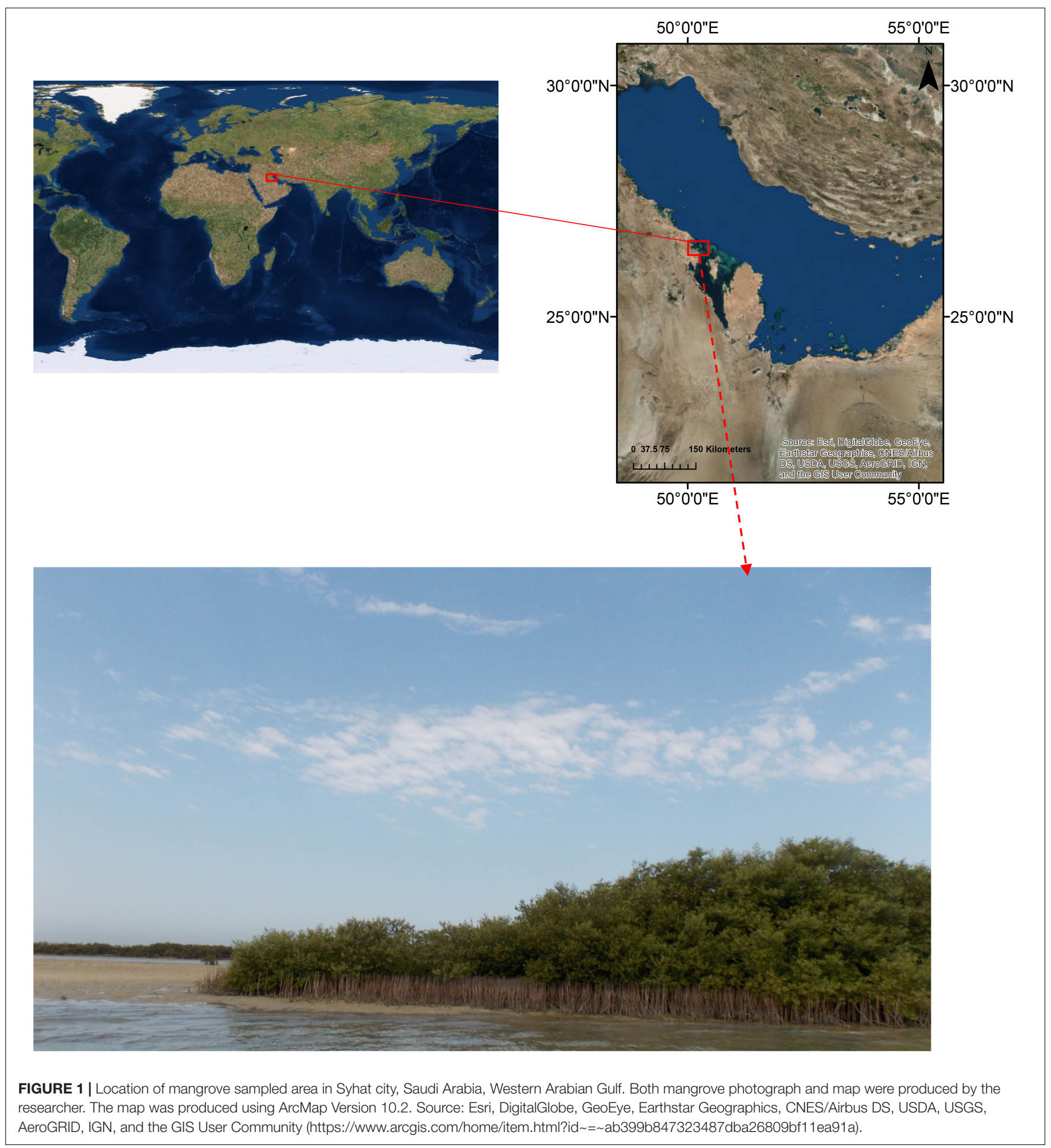

South East (SE) Thailand. Also, Almahasheer et al. (2016) selected a variable number of $A$. marina between 30 and 75 trees among diverse locations in the Central Red Sea.

Because the plant repeats models (e.g., nodes, leaves, and roots), counting nodes in axillary shoots and apical shoots is equivalent (Duke and Pinzon, 1992). Therefore, the number of nodes that plants produce annually in each measured (branches/axillary shoot, $n=40$ ) was estimated according to Duarte et al. (1999) and Almahasheer et al. (2016).

\section{Internodal and Annual Growth Estimation}

Mangrove growth can be reconstructed based on cycles of internodal length (Duarte et al., 1999), which allows us to evaluate the internodal production and the yearly growth by measuring 
the distance between every two nodes. The main criteria for selecting a tree are the clarity of following and seeing the complete branch or axis. The first step is to count and measure all nodes from the apical meristem or the axillary meristem.

The measurements of each node were arranged in sequential order, starting from the meristem to the hypocotyl. As a result, a long-term filter with a running average of $n=14$ was created to eliminate long-term variability and was then subtracted from the raw sequences. Later, a short-term filter was subsequently produced by filtering the data to remove short-term variability with a consecutive average of $n=3$ and $n=4$. Two short-term filters were used in order to double-check the results.

The annual growth was calculated as the sum of the length of the internodal cycle for each (branches/axillary shoot) separately (i.e., from the measured distance between the nodes for each identified cycle, Figure 2).

\section{Plastochrone Interval (PI) Estimation}

To calculate the plastochrone interval (PI) (i.e., the average time in between the production of a node) (Gill and Tomlinson, 1971) was calculated as the average ratio between the time elapsed and the number of nodes produced annually.

\section{Statistical Analysis}

Statistical analyses, including descriptive statistics (i.e., mean, maximum, minimum, median, SD, SE, and upper and lower 95\%CI), were carried out using JMP Pro 13, a computer program for statistics developed by the Statistical Analysis System (SAS) Institute.

\section{RESULTS}

The node production in 40 branches/axillary shoot in Syhat city, Saudi Arabia, ranged from 6 to 9 nodes $\mathrm{y}^{-1}$ for the averages of both running short filters $n=3$ and $n=4$, with a mean of 7.1 nodes $y^{-1}$ and a median of 7 nodes $y^{-1}$ (Figure 3A). Hence, the number of nodes that branches produce yearly was translated to days, which means that the PI calculated ranged from 40.5 to 60.8 days for the averages of both running short filters $n=3$ and $n=4$, with a mean of 51.4-51.9 days and a median of 52 days (Figure 3B).

The annual cycles of the internodal length represent the branch growth rate in centimeters per year, which (ranged from 12 to $43 \mathrm{~cm}$; median of $19 \mathrm{~cm}$ ) for minima to minima point and (from 15 to $46.5 \mathrm{~cm}$; median of $25.5 \mathrm{~cm}$ ) for maxima to maxima point (Figures 2, 3C).

\section{DISCUSSION}

In general, plants repeat few models while growing, e.g., internodes, leaves, and roots (Duarte et al., 1999). Node production of $A$. marina in this study ranged from 6 to 9 nodes $\mathrm{y}^{-1}$, with an average of 7.1 nodes $\mathrm{y}^{-1}$, which is slightly lower than that reported from the Red Sea (9.44 nodes subbranch $\mathrm{y}^{-1}$ Almahasheer et al., 2016), nevertheless, within the range of other mangrove species that produced 3.8 nodes $\mathrm{y}^{-1}$ in Panama to 30 nodes $\mathrm{y}^{-1}$ in Thailand (Duke and Pinzon, 1992; Thampanya et al., 2002), and consistent with Rhizophora apiculata of 7.3 nodes $\mathrm{y}^{-1}$ in Southeast (SE) Asia (Duarte et al., 1998). Additionally, the PI of this study ranged from 40.5 to

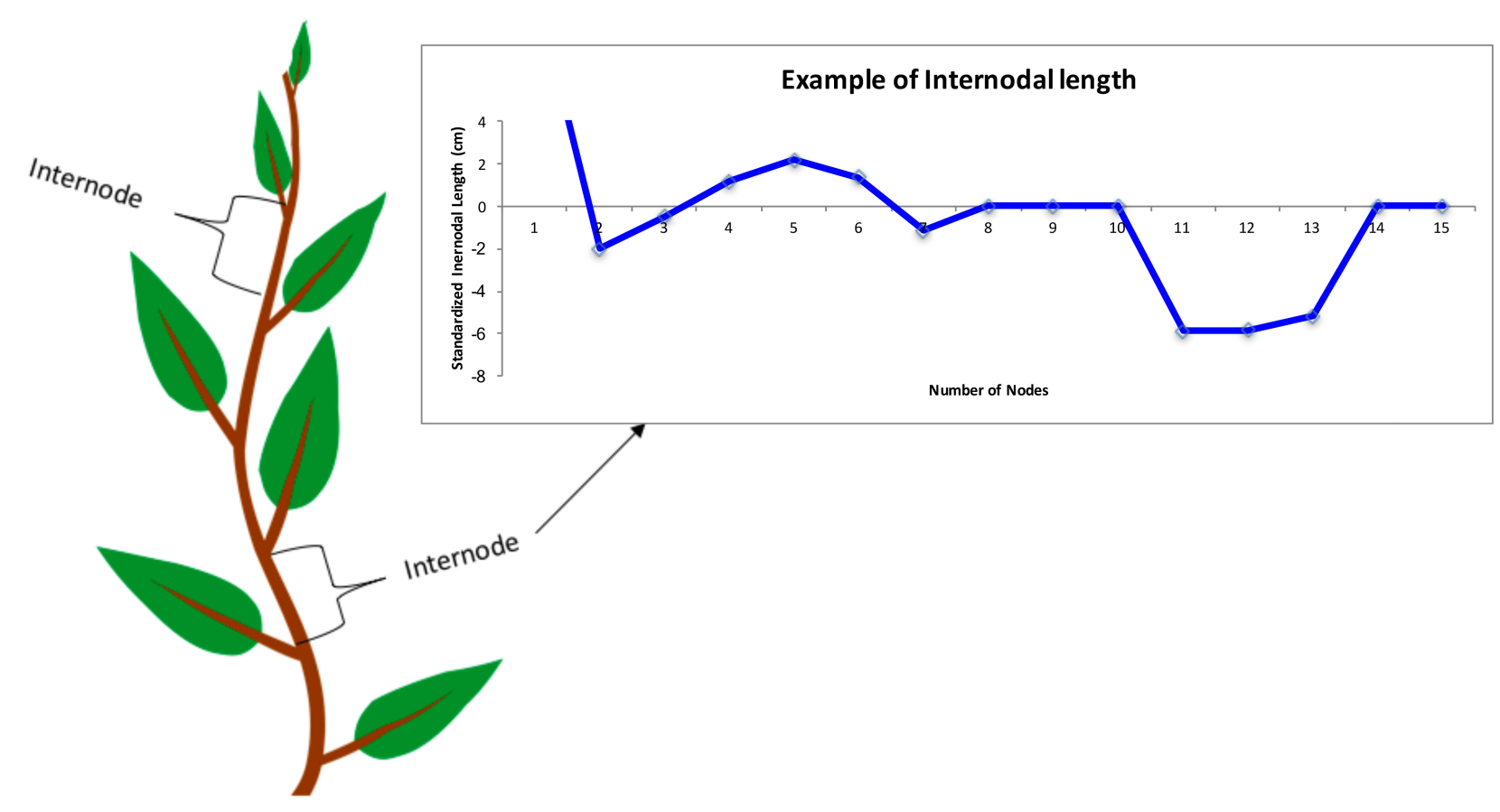

FIGURE 2 | An example of measuring a node on a branch and then analyzing the internodal length. 
60.8 days with an average of 52 days, higher than the PI of Red Sea A. marina of 39 days (Almahasheer et al., 2016), whereas stem elongation of branches in this study averaged from 20 to $28 \mathrm{~cm}$ equivalent to the annual growth of $A$. marina in King Abdullah Economic city located in the Central Red Sea (Almahasheer et al., 2016). The slow growth of A. marina in this region is possible because of the harsh environmental conditions of the Arabian Gulf (Sheppard et al., 2010), along with the effects of major pollutions affecting the area, e.g., 1991 oil spill (Price, 1998), and their position at the nethermost limit of their dispersal (Duke, 1990).

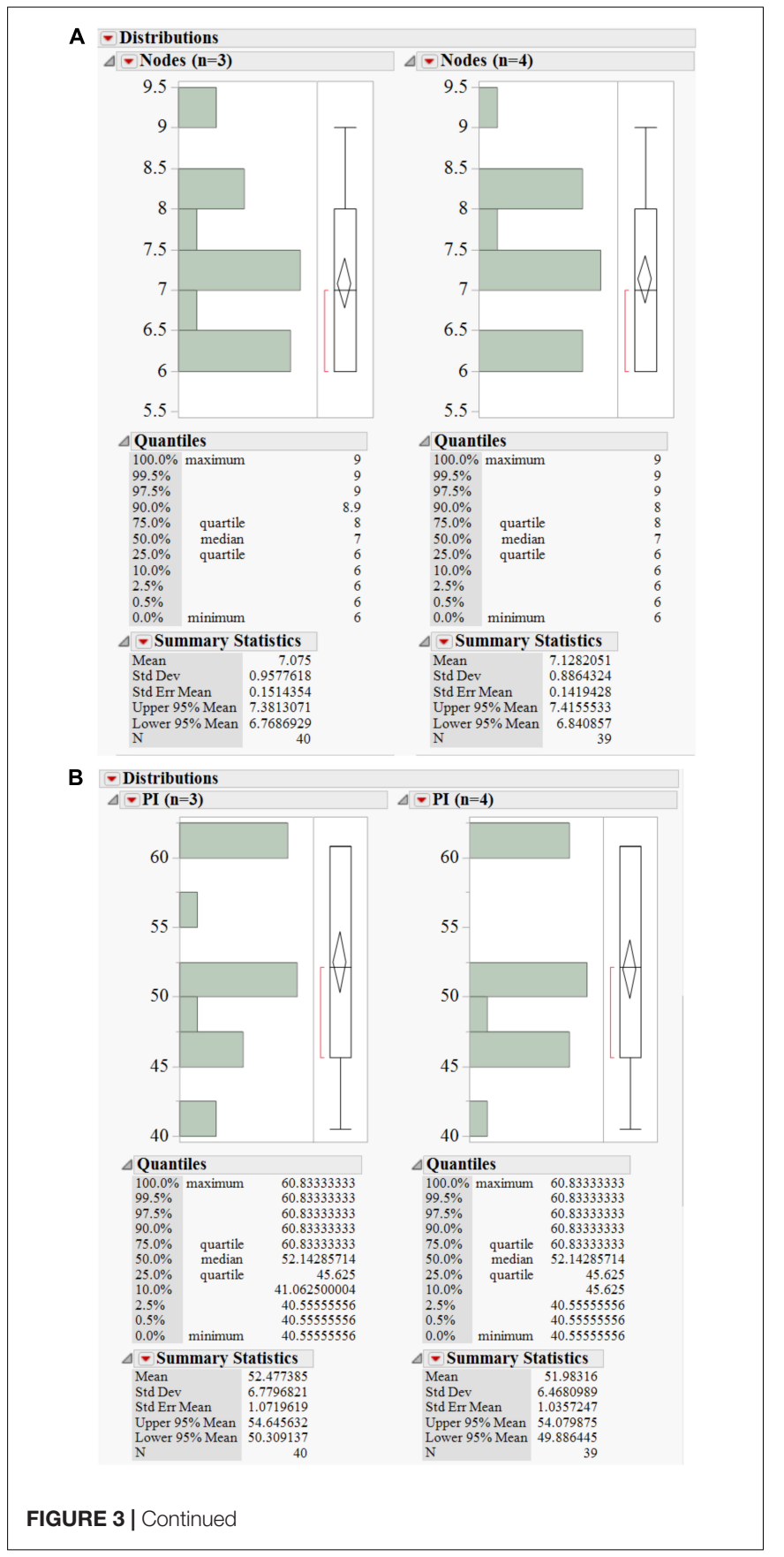

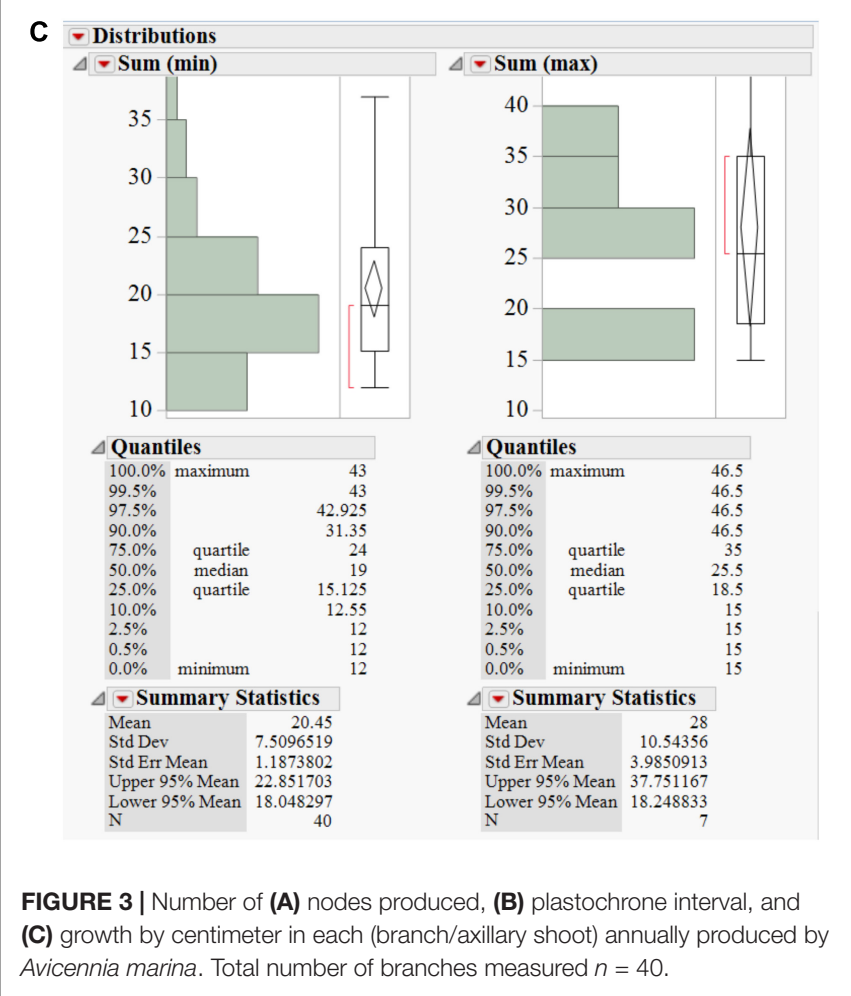

\section{CONCLUSION}

The results obtained within the study are essential for several applications, from the planning of restoration and monitoring activities to reproduction estimates via simple measurements. However, a comprehensive study of internodal analysis across different locations and population dynamics of A. marina in the Arabian Gulf is necessary and urgent. In particular, this area is characterized by a hyperarid environment that could be seen as a natural incubator to evaluate future climate change effects.

\section{DATA AVAILABILITY STATEMENT}

The original contributions presented in the study are included in the article/supplementary material. Further inquiries can be directed to the corresponding author/s.

\section{AUTHOR CONTRIBUTIONS}

The author confirms being the sole contributor of this work and has approved it for publication.

\section{FUNDING}

The author received no financial support for the research of this article. 


\section{ACKNOWLEDGMENTS}

The author thankful to the Department of Biology, College of Science, Imam Abdulrahman Bin Faisal

\section{REFERENCES}

Almahasheer, H. (2018). Spatial coverage of mangrove communities in the Arabian Gulf. Environmental Monitoring and Assessment 190, 85.

Almahasheer, H., Duarte, C. M., and Irigoien, X. (2016). Phenology and Growth dynamics of Avicennia marina in the Central Red Sea. Scientific Reports 6, 37785 .

Barbier, E. B., Hacker, S. D., Kennedy, C., Koch, E. W., Stier, A. C., and Silliman, B. R. (2011). The value of estuarine and coastal ecosystem services. Ecological Monographs 81, 169-193.

Duarte, C. M., Geertz-Hansen, O., Thampanya, U., Terrados, J., Fortes, M. D., Kamp-Nielsen, L., et al. (1998). Relationship between sediment conditions and mangrove Rhizophora apiculata seedling growth and nutrient status. Marine Ecology Progress Series (MEPS) 175, 277-283. doi: 10.3354/meps 175277

Duarte, C. M., Thampanya, U., Terrados, J., Geertz-Hansen, O., and Fortes, M. D. (1999). The determination of the age and growth of SE Asian mangrove seedlings from internodal counts. Mangroves and Salt Marshes 3, 251-257.

Duke, N. (1990). Phenological trends with latitude in the mangrove tree Avicennia marina. The Journal of Ecology 1990, 113-133. doi: 10.2307/2261040

Duke, N. C., and Pinzon, Z. S. M. (1992). Aging Rhizophora seedlings from leaf scar nodes: a technique for studying recruitment and growth in mangrove forests. Biotropica 1992, 173-186. doi: 10.2307/2388671

Gill, A. M., and Tomlinson, P. B. (1971). Studies on the growth of red mangrove (Rhizophora mangle L.) 3. Phenology of the shoot. Biotropica 1971, 109-124. doi: $10.2307 / 2989815$

Hegazy, A. K. (1998). Perspectives on survival, phenology, litter fall and decomposition, and caloric content of Avicennia marina in the Arabian Gulf region. Journal of arid environments 40, 417-429. doi: 10.1006/jare.1998.0457

Price, A. (1998). Impact of the 1991 Gulf War on the coastal environment and ecosystems: current status and future prospects. Environment international 24, 91-96. doi: 10.1016/s0160-4120(97)00124-4

Price, A. R. G., Sheppard, C. R. C., and Roberts, C. M. (1993). The Gulf: Its biological setting. Marine Pollution Bulletin 27, 9-15. doi: 10.1016/0025326X(93)90004-4
University (IAU). The author also thankful to the two reviewers for their insightful comments that significantly improved the manuscript and also to Christine Nelson for editing the manuscript.

Sheppard, C., Al-Husiani, M., Al-Jamali, F., Al-Yamani, F., Baldwin, R., Bishop, J., et al. (2010). The Gulf: A young sea in decline. Marine Pollution Bulletin 60, 13-38. doi: 10.1016/j.marpolbul.2009.10.017

Thampanya, U., Vermaat, J. E., and Duarte, C. M. (2002). Colonization success of common Thai mangrove species as a function of shelter from water movement. Marine Ecology Progress Series 237, 111-120. doi: 10.3354/meps23 7111

Tomlinson, P. (1986). The botany of mangroves. Cambridge tropical biology series. Cambridge: Cambridge University Press.

Yasseen, B. T., and Abu-Al-Basal, M. A. (2008). Ecophysiology of Limonium axillare and Avicennia marina from the coastline of Arabian GulfQatar. Journal of Coastal Conservation 12, 35-42. doi: 10.1007/s11852-0080021-Z

Zahed, M. A., Ruhani, F., and Mohajeri, S. (2010). An overview of Iranian mangrove ecosystem, northern part of the Persian Gulf and Oman Sea. Electronic Journal of Environmental, Agricultural and Food Chemistry 9, 411417.

Conflict of Interest: The author declares that the research was conducted in the absence of any commercial or financial relationships that could be construed as a potential conflict of interest.

Publisher's Note: All claims expressed in this article are solely those of the authors and do not necessarily represent those of their affiliated organizations, or those of the publisher, the editors and the reviewers. Any product that may be evaluated in this article, or claim that may be made by its manufacturer, is not guaranteed or endorsed by the publisher.

Copyright (C) 2021 Almahasheer. This is an open-access article distributed under the terms of the Creative Commons Attribution License (CC BY). The use, distribution or reproduction in other forums is permitted, provided the original author(s) and the copyright owner(s) are credited and that the original publication in this journal is cited, in accordance with accepted academic practice. No use, distribution or reproduction is permitted which does not comply with these terms. 